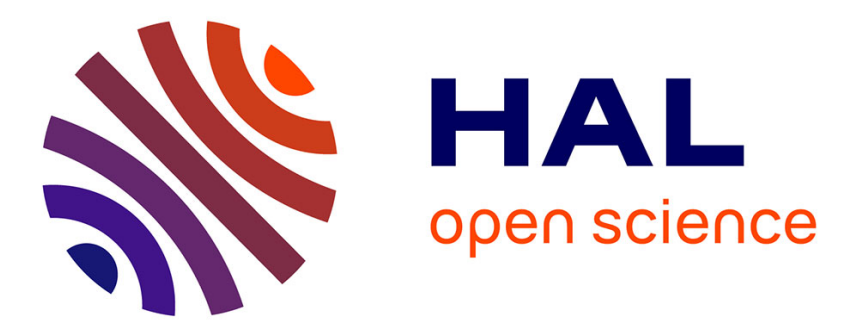

\title{
A Clinical Report of Bone Regeneration in Maxillofacial Surgery using Bonelike ® Synthetic Bone Graft
}

R.C. Sousa, J.V. Lobato, A.C. Maurício, N.S. Hussain, C.M. Botelho, M.A. Lopes, J.D. Santos

\section{- To cite this version:}

R.C. Sousa, J.V. Lobato, A.C. Maurício, N.S. Hussain, C.M. Botelho, et al.. A Clinical Report of Bone Regeneration in Maxillofacial Surgery using Bonelike ® Synthetic Bone Graft. Journal of Biomaterials Applications, 2008, 22 (4), pp.373-385. 10.1177/0885328207078260 . hal-00570783

\section{HAL Id: hal-00570783 https://hal.science/hal-00570783}

Submitted on 1 Mar 2011

HAL is a multi-disciplinary open access archive for the deposit and dissemination of scientific research documents, whether they are published or not. The documents may come from teaching and research institutions in France or abroad, or from public or private research centers.
L'archive ouverte pluridisciplinaire HAL, est destinée au dépôt et à la diffusion de documents scientifiques de niveau recherche, publiés ou non, émanant des établissements d'enseignement et de recherche français ou étrangers, des laboratoires publics ou privés. 


\title{
A Clinical Report of Bone Regeneration in Maxillofacial Surgery using Bonelike ${ }^{\circledR}$ Synthetic Bone Graft
}

\author{
R. C. SOUSA \\ Serviço de Estomatologia e Cirurgia Maxilofacial - Hospital Geral de Santo \\ António, Largo Abel Salazar, 4050, Porto, Portugal \\ J. V. LOBATO \\ Departamento de Estomatologia Centro Hospitalar de Vila Nova de Gaia \\ (CHVNG), Rua Conceição Fernandes, 4434-502, Vila Nova de Gaia, Portugal
}

\section{A. C. MaURício}

Departamento de Clínicas Veterinárias, Instituto de Ciências Biomédicas de Abel Salazar (ICBAS), Universidade do Porto (UP), Largo Professor Abel Salazar, 2, 4099-003, Porto Portugal

Centro de Estudos de Ciência Animal (CECA), Instituto de Ciências e Tecnologias Agrárias e Agro-Alimentares (ICETA), Universidade do Porto (UP), Campus Agrário de Vairão, Rua Padre Armando Quintas 4485-661, Vairão, Portugal

N. S. Hussain, C. M. Botelho, M. A. Lopes AND J. D. SANToS* Instituto de Engenharia Biomédica, Laboratório de Biomateriais, Rua Campo Alegre, 823, 4150-180, Porto, Portugal

Departamento de Engenharia Metalúrgica e de Materiais (DEMM) Faculdade de Engenharia da Universidade (FEUP), Dr. Roberto Frias 4200-465, Porto Portugal

\footnotetext{
*Author to whom correspondence should be addressed. E-mail: jdsantos@fe.up.pt Figures 2-4 appear in color online: http://jba.sagepub.com
} 


\begin{abstract}
The objective of this study is to evaluate the osteoconductivity and bioactivity of the Bonelike ${ }^{\circledR}$ graft in repairing surgical cystic bone defects. Bonelike $^{\circledR}$ is implanted in 11 patients, aged between 24 and 53 years with a mean age of 36 years, consisting of 5 men and 6 women. According to the standard follow up protocols, radiological examinations are performed and Bonelike $^{\circledR} /$ bone retrieved samples have been analyzed histologically using nondecalcified sections obtained perpendicular to bone length axis. Radiographic examination and histological results clearly demonstrate an extensive new bone formation apposed on Bonelike ${ }^{\circledR}$ granules with a significant degree of maturation. These clinical applications in maxillary bone defects indicate perfect bone bonding between new bone formed and Bonelike ${ }^{\mathbb{R}}$ granules, along with partial surface biodegradation. This quick and effective osteoconductive response from Bonelike ${ }^{\circledR}$ may reduce the time needed to reconstruct the bone defected area of patients.
\end{abstract}

KEY WORDS: Bonelike ${ }^{\circledR}$, bone regeneration, maxillofacial surgery, histological studies.

\title{
INTRODUCTION
}

$\mathbf{O}$ steoconductive materials refer to scaffolds that provide the appropriate framework for bone to grow in sites where bone naturally occurs and therefore, they function as substrates on which locally residing osteoblasts can attach. These materials rely on the presence of sufficient inorganic and organic species in the local environment to direct the bone formation process and depend on direct physical contact with exposed surfaces of viable bone [1]. Often, sufficient autogenous bone is not available or would require an additional time for surgery and these factors may be unacceptable in some clinical situations. Allogenic bone, obtained from another individual of the same specie provides an alternative to autogenous grafts but the fear of disease transmission persists [2,3]. This fear has driven the market to produce clinically beneficial alternatives to human allograft tissue [4]. Doron and Amy [5] reports an overview of the basic concepts of bone grafting and discussed the most commonly used bonegraft substitutes and their potential indications. Synthetic bone-graft substitutes are available in different forms including blocks, granules, cements, gels, and strips [6]. Examples of osteoconductive scaffolds include materials such as $\beta$-tricalcium phosphate $\left(\beta\right.$-TCP), $\beta$-Ca $\mathrm{Ca}_{3}\left(\mathrm{PO}_{4}\right)_{2}$, or hydroxyapatite $(\mathrm{HA}), \mathrm{Ca}_{10}\left(\mathrm{PO}_{4}\right)_{6}(\mathrm{OH})_{2}$. Although these materials were found to be useful as bone fillers, HA and $\beta$-TCP have specific drawbacks [7]. Produced to date crystalline forms of HA undergo osseointegration but have a low solubility compared to the rate of new bone formation $[8,9]$. On the other hand, $\beta$-TCP's rate of bioresorption 
has proved to be too rapid and in an unpredictable way [7]. In order to design a scaffold that supports bone formation while gradually being replaced by bone, an optimum balance between a more stable phase like HA and a more soluble phase like TCP is essential [10]. Therefore, the incorporation of a CaO- $\mathrm{P}_{2} \mathrm{O}_{5}$ based glass in the $\mathrm{HA}$ matrix was envisaged as an easier way to produce a material to achieve this goal.

Santos et al. [11-14] developed a new biomaterial by the incorporation of glass based on a $\mathrm{P}_{2} \mathrm{O}_{5}$ system into the HA structure by a liquid sintering process. This glass reinforced HA (GR-HA) was recently patented and registered as Bonelike ${ }^{\circledR}$. This system allows the incorporation of different ions into the HA structure, such as magnesium, sodium, and fluoride, resulting in a bone graft with a closer chemical composition to the mineral phase of human bone [11-13]. Additionally, it has been shown that the incorporation of a glass into the HA structure enhances its mechanical properties [13]. Another advantage of this system developed by Santos et al. is the ability to control the percentage of secondary phases ( $\alpha$ and $\beta$-TCP) present by the incorporation of different percentages of glass.

The improved in vitro biological performance of Bonelike ${ }^{\circledR}$ has been reported by the use of human bone marrow osteoblastic cells, and this behavior is related to its chemical composition. Several animal studies have also been performed using Bonelike ${ }^{\circledR}$, and push-out tests and histological analysis demonstrated a good osseointegration of Bonelike ${ }^{\circledR}$ [15-17]. Furthermore, histomorphometric studies indicated that the rate of new bone formation was higher when compared to control samples of HA.

In order to facilitate the use of Bonelike ${ }^{\circledR}$ in different clinical applications (e.g., sinus elevation), the Bonelike ${ }^{\circledR}$ can be associated to a resorbable matrix. Animal studies showed that the use of a resorbable matrix does not influence the bioactivity of Bonelike ${ }^{\circledR}$ [17]. Bonelike ${ }^{\circledR}$ has already been used with great success in several medical applications like implantology as coated implants and orthopedics surgery $[18,19]$. For example, a very recent study [19] on histomorphometric measurements, histological and scanning electron microscopy (SEM) analyses of bone-implant interface of retrieved samples have proved the highly osteoconductive properties of Bonelike ${ }^{\circledR}$ in orthopedic applications.

Eleven patients presented large bone defects resulting from the removal of bone cysts, so that in order to enhance bone regeneration and preserve the jaw volume and contour, the Bonelike ${ }^{\circledR}$ granules were used. Radiographic and histological analyses were performed to evaluate new bone formation and to study the interface between Bonelike ${ }^{\circledR}$ and the new bone. 


\section{PATIENTS AND METHODS}

\section{Bonelike $^{\circledR}$ Preparation and Characterization}

In the present study, Bonelike ${ }^{\circledR}$ granules size ranging from 250 to $500 \mu \mathrm{m}$ were prepared as follows. First, a CaO- $\mathrm{P}_{2} \mathrm{O}_{5}$ based glass with the composition of $65 \mathrm{P}_{2} \mathrm{O}_{5}-15 \mathrm{CaO}-10 \mathrm{CaF}_{2}-10 \mathrm{Na}_{2} \mathrm{O}$ in mol\% was obtained from reagent grade chemicals by using a platinum crucible at $1450^{\circ} \mathrm{C}$ for $2 \mathrm{~h}$. The glass was crushed in an agate mortar and sieved up to a granule size $<75 \mu \mathrm{m}$. The Bonelike ${ }^{\circledR}$ was prepared by mixing $2.5 \%(\mathrm{w} / \mathrm{w})$ of glass with laboratory prepared pure phase HA in iso-propanol. The mixed powders were dried for $24 \mathrm{~h}$ at $60^{\circ} \mathrm{C}$ and sieved to a particle size $<75 \mu \mathrm{m}$ and then isostatically pressed at $200 \mathrm{MPa}$. The Bonelike ${ }^{\circledR}$ was sintered at $1300^{\circ} \mathrm{C}$ for $1 \mathrm{~h}$, crushed, and then sieved to the desirable particle size range. Finally, sterilization of Bonelike ${ }^{\circledR}$ granules was performed by autoclave at $121^{\circ} \mathrm{C}$ for $35 \mathrm{~min}$.

X-ray diffraction (XRD) and Rietveld analysis was performed to identify and quantify the percentage of crystalline phases present in the microstructure of Bonelike ${ }^{\circledR}$ using a Siemens D 5000 diffractometer with $\mathrm{Cu}-\mathrm{K} \alpha$ radiation $(\lambda=1.5418 \AA)$. The scans were performed between 24 and $42^{\circ}$ (2) with a step size of $0.02^{\circ}$ and a count time of $2 \mathrm{~s} / \mathrm{step}$.

\section{Clinical Features}

For repairing surgical maxillary cystic bone defects, patients were selected strictly on the basis of their clinical needs and according to the following criteria, which included: patients of any age, any sex, any weight, patients without any systemic disease, or infection, noncharacterized maxillary or mandibular cystic lesion up to $12 \mathrm{~cm}$ long and the cyst removed is a true bony cyst. The exclusion criteria were systemic unhealthy patients, infected cystic cavities, acute or chronic infection at local bone defect, bone inflammatory diseases, particularly osteomyelitis, malignant tumors, severe renal dysfunctions, and patients with non-controlled bone metabolism.

In the present study, 11 patients of both sexes, being 5 males and 6 females, ranging from 24 to 53 years with a mean age of 36 years have been considered. Cavity size varied from $3 \mathrm{~cm}$ in diameter in the minor lesion up to $12 \mathrm{~cm}$ in the largest lesion (Table 1). All cases were operated under general anesthesia, according to a head and neck surgical protocol, in a main hospital theater. Through a transgingival surgical approach making up a wide muco-periosteal flap, being this, the main surgical access to the bony lesion. Once attained its entire exposition, 
Table 1. Cyst volume and dimensions in each case.

\begin{tabular}{lcc}
\hline Case no. & Largest cyst dimension $(\mathrm{cm})$ & Cyst volume $(\mathrm{appr}).\left(\mathrm{cm}^{3}\right)$ \\
\hline 1 & 2.4 & 9.6 \\
2 & 12.0 & 152.0 \\
3 & 7.0 & 52.0 \\
4 & 2.5 & 18.7 \\
5 & 3.0 & 21.0 \\
6 & 4.0 & 36.0 \\
7 & 3.0 & 11.2 \\
8 & 3.0 & 9.0 \\
9 & 3.0 & 18.0 \\
10 & 4.0 & 24.0 \\
11 & 3.0 & 12.0 \\
\hline
\end{tabular}

osteotomy was done to isolate the 'cystic lesion wall', by scrapping and drilling all the pathological tissues until all were carefully removed. In the teeth bearing areas of both maxilla and mandible, whenever a tooth route was involved a previous endodontic treatment was performed, followed by a suitable apicectomy.

To determine the cyst volume a balloon $\left(\right.$ Solycil $\left.^{\circledR}\right)$ was inserted into the bone defect. The balloon was filled with saline solution $(\mathrm{NaCl} 0.9 \%$, Braun $^{\circledR}$ ) through a catheter. The volume of saline solution that could fill the balloon located inside the cyst was the volume of the cyst. Cysts with a volume $>10 \mathrm{~cm}^{3}$ were measured by computer tomography (CT)-scan images. After the complete removal of the cystic tissue, the remaining bone cavities were firmly packed with Bonelike ${ }^{\circledR}$ granules, blood and crushed bone remnants, to completely fill the bony cavities and 'to sculpt' the cortical bone contour. Primary closure of the mucosa was performed using a reabsorbable suture and care was taken to ensure sufficient mobility of the mucosal flap to cover the granules.

Pre-operative CT-scans and post-operative radiological examinations were performed according to the standard follow-up protocol.

Among the 11 studied cases, histological analyses have been performed for only one patient (referred to as Case No. 2). Operating on a second time surgery for dental implant placement and under formal consent, a bone block $\left(1.0 \times 0.5 \times 0.5 \mathrm{~cm}^{3}\right)$ was taken from implant/ patient bone transition. In this case, the selected biopsy was retrieved after 48 weeks of implantation and placed immediately in a neutral formaldehyde fixative solution $(6 \%)$ for one week period, followed by dehydration in a series of alcohol solutions and finally embedded in resin. Non-decalcified sections of $40 \pm 10 \mathrm{~mm}$ were obtained from the 
resin blocks, after cutting these forms in the perpendicular direction of the bone length axis using a diamond saw. These sections were stained with hematoxylin/eosin and Solo-Chrome $\mathrm{R}$ and examined using an Olympus BH-2 transmitted light microscope and scanning electron microscopy (SEM).

\section{RESULTS}

Figure 1 depicts an X-ray diffraction pattern of Bonelike ${ }^{\circledR}$. Rietveld analysis previously reported showed that Bonelike ${ }^{\circledR}$ is composed by $68.4 \%$ of HA, $24 \%$ of $\alpha$-TCP, and 7.6\% of $\beta$-TCP [11-13]. For a successful regeneration, it is essential that the implant material is degraded or resorbed at a similar rate to the rate of bone formation. As it has been widely demonstrated in the literature [20-22] the phases present on Bonelike ${ }^{\circledR}$ can be degraded in vivo, HA has a slow degradation rate and TCP has a faster degradation rate. The combination of the two phases allows the degradation rate of Bonelike ${ }^{\circledR}$ to be controlled to reflect the rate of bone regeneration.

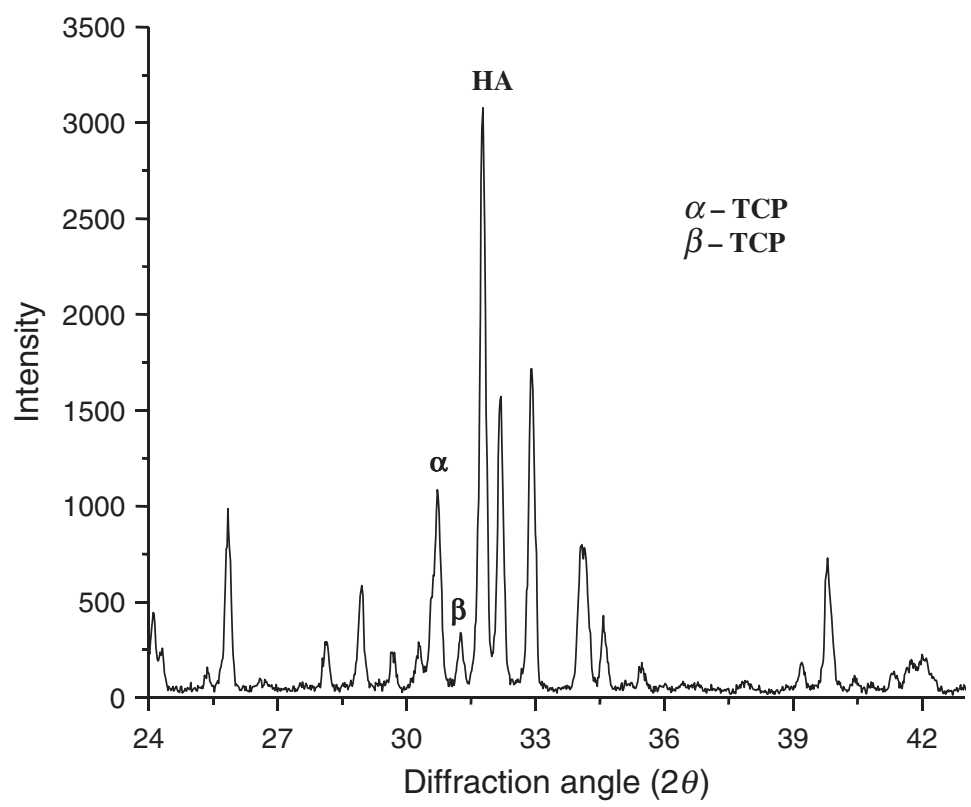

Figure 1. X-ray diffraction of Bonelike ${ }^{\circledR}$ graft, which is composed of HA, $\beta$ - and $\alpha$-TCP phases. 
Most cysts of the oral and facial regions under treatment were located within the jaws as an intra bony lesion. Figure 2 shows a nonodontogenic cyst in the midline aspect of the mandible. Large and multi loci lesions may considerably complicate the post-operative treatment. In some clinical cases the resection of a large segment of the jaw was necessary to insure complete removal of the lesion, so the pathological 'tissue destruction' process and its suitable surgical removing led to a massive bone loss.

It has been reported that the use of filling material substantially decreases the time required for the healing of a bone defect in comparison with the traditional technique (no filling material). Additionally, there is no record of post-operative infection, foreign body reaction, or tear of the mucosa, independent of the cysts size, when a filling material was used. Table 1 presents the cyst's diameter and volume in each clinical case, where it is possible to observe that the smallest and largest cysts are 2.4 and $12 \mathrm{~cm}$ in diameter, respectively. Similarly, the cyst volume varied from 9 to $152 \mathrm{~cm}^{3}$. An in-depth radiological follow-up was performed to all patients. It is noteworthy that in 10 out of 11 patients the first control was carried out immediately after surgery, the second control was performed 6-12 weeks after surgery ( 8 out of 11 patients), the third and fourth control were done after $24-36$ weeks and 36-48 weeks, in 10 and 7 patients, respectively.

One representative clinical case of the use of Bonelike ${ }^{\circledR}$ is demonstrated in Figure 3. Figure 3(A) shows the gingival and periosteal tissue

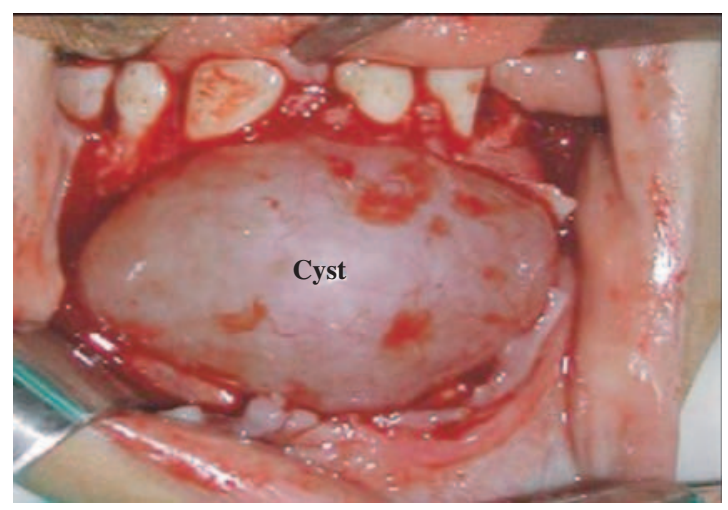

Figure 2. Frontal view showing simphysis mandibular cyst that was excised and later filled with Bonelike ${ }^{\circledR}$ granules in order to regenerate the bone defect. 


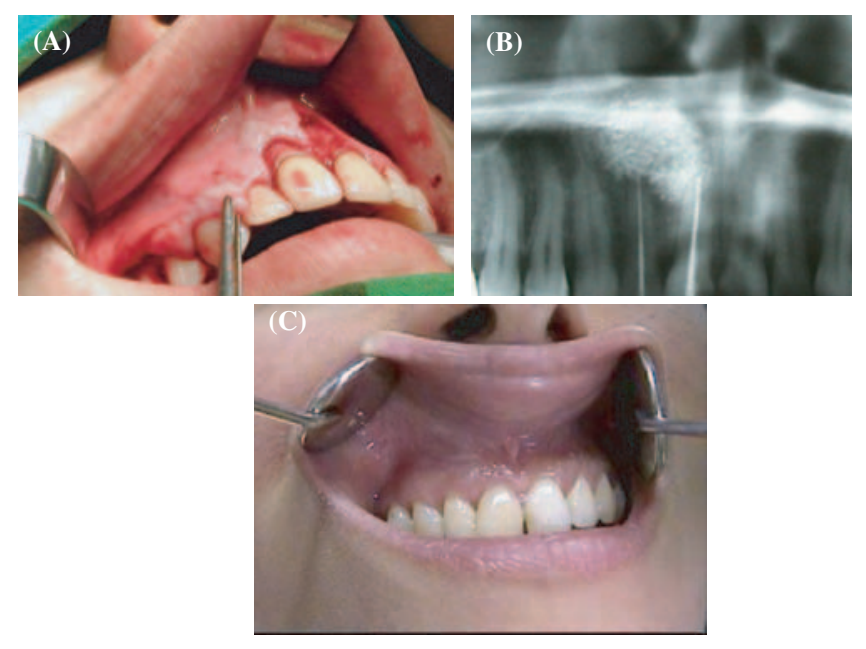

Figure 3. (A) A gingival and periosteal tissue covering the entire maxillary cystic lesion, (B) post-operative radiograph shows the excellent Bonelike ${ }^{\circledR}$ granules adaptation to the bone cavity without any sings of material dislocation after 12 weeks (C) complete restoration of the bone defect and biofunctionality may be seen 48 weeks after implantation.

covering the entire maxillary cystic lesion. After 12 weeks of implantation, the post-operative radiological analysis showed excellent granules adaptation to the host cavity without material dislocation accompanied and partial regeneration of the bone defect (Figure 3(B)). After 48 weeks of implantation, a complete restoration of the local biofunctionality was achieved (Figure 3(C)). The histology analysis of the biopsy performed after 48 weeks showed a mineralized matrix in the grafted area and mature lamellar bone was observed close to and in contact with Bonelike $^{\circledR}$ granules (Figure 4(A)). Active angiogenesis, with a large number of blood vessels throughout the osteoid matrix was also seen (Figure 4(A)). Some degradation of Bonelike ${ }^{\circledR}$ granules can also be seen as shown in Figure 4(B).

\section{DISCUSSION}

The present clinical report shows that the use of Bonelike ${ }^{\circledR}$ aids the recovery of the patients restoring the biofunctionality of the affected area. After 48 weeks of implantation there is significant bone regeneration and all patients are recovering from their bone lesions and did not present any symptoms of rejection or infections. 

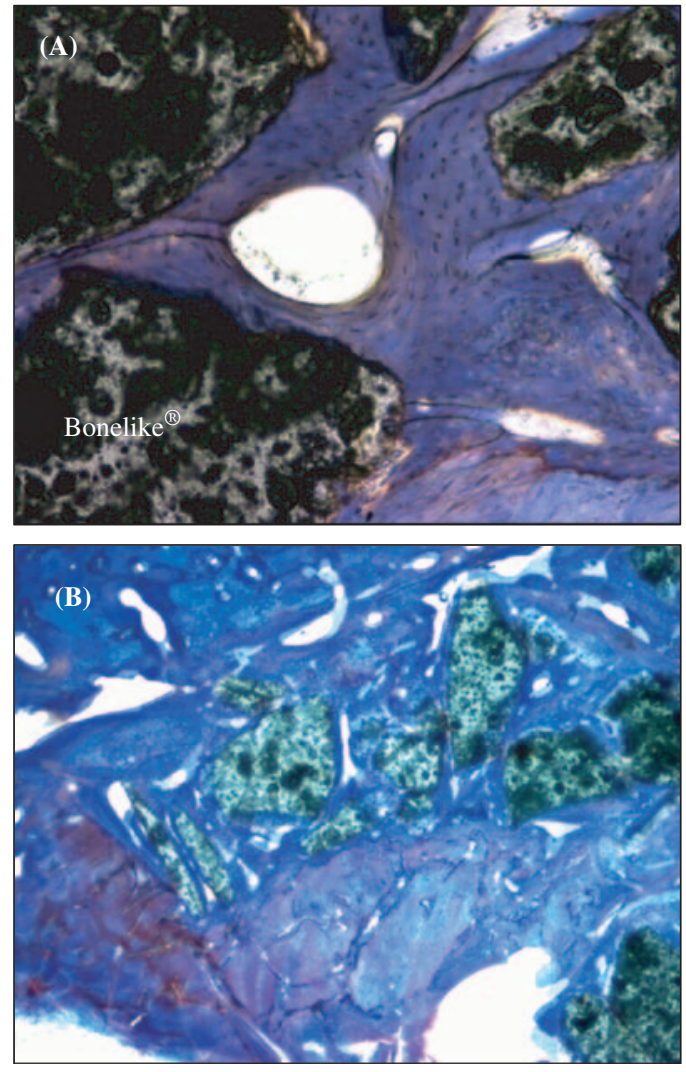

Figure 4. Histological images of Bonelike ${ }^{\circledR}$ granules implanted after 48 weeks show new bone formation around granules with the formation of blood vessels throughout the osteoid matrix due to active angiogenesis (A); Bonelike ${ }^{\circledR}$ resorption could also be observed, which indicates that this novel bone graft shows controlled biodegradation in vivo conditions (B), (Original magnification $400 \times$, Solo-Chrome R staining).

As mentioned earlier, Bonelike ${ }^{\circledR}$ has a composition similar to that of the mineral phase of bone, the presence of controlled biodegradable $\beta$ - and $\alpha$-TCP phases into its structure results in a local enrichment in $\mathrm{Ca}^{2+}, \mathrm{P}^{5+}, \mathrm{Na}^{+}$, and $\mathrm{F}^{-}$into the physiological environment, which stimulate new bone formation. The presence of a more stable phase like HA provides a scaffold for the attachment of bone cells that will support bone formation. It has been widely demonstrated in the literature that $\beta$ - and $\alpha$-TCP can be degraded in vivo and that HA is a bioactive material [20-22]. 
In this clinical report, the ratio of remnant bone to synthetic graft varied from case to case and in accordance with cavity volume and amount of collected bone. Nevertheless, about $1 / 3$ of total filling was patient's own bone. Therefore, bone healing occurred from the periphery of the cystic cavity to the center with a controlled process in which the filling material served as a matrix to conduct bone cells as it could be observed in X-ray images. In the case of non filled cystic cavities, the healing process was slower and normally it is observed as a regenerated bone volume default $[23,24]$.

In the present study, the histology showed that Bonelike ${ }^{\circledR}$ granules were being resorbed and that they were surrounded by new bone. The new bone presented a lamellar-like structure and filled spaces between implanted granules, as well as established direct contact between the surface of the biomaterial and the bone matrix. No inflammatory cells or fibrous tissue was seen surrounding the implant. The osteoid matrix presented several blood vessels indicating an active angiogenic process.

The formation of a vascular network simultaneous to the formation of new bone is extremely important; this network is vital for cellular viability. It is through this network that oxygen and nutrients reach the cells, and this network is also responsible for the removal of waste products [25]. Another important function of this network is the transport of progenitor cells and several cytokines and growth factors required for balanced bone regeneration. The angiogenesis process, formation of a vascular network from pre-existent blood vessels and the osteogenesis process, formation of new bone tissue at the defect site is interconnected in a structural, biochemical, and functional way [25]. Therefore, the ability of a bone graft to induce or allow the formation of this network is very important.

In this report it has been shown that Bonelike ${ }^{\circledR}$ not only has the ability to stimulate bone regeneration, but also has the ability to stimulate the formation of a vascular network. Hence, Bonelike ${ }^{\circledR}$ is an excellent scaffold for developing of bone regeneration process.

The results presented in this clinical report corroborate previous results in different clinical applications, such as in implantology and orthopedics where histomorphometric measurements, and histological and SEM analyses of bone-implant interface demonstrated the high osteoconductive properties of this bone graft $[18,19,26]$. It has been shown that after 6 months of implantation in a human tibia, the contact between Bonelike ${ }^{\circledR} /$ de novo bone was approximately of $67 \%$ and after 12 months this value can reach $84 \%$. 


\section{CONCLUSIONS}

After 48 weeks of implantation with Bonelike ${ }^{\circledR}$ all the patients showed high bone regeneration, they are recovering from their bone lesions and none of the patients presented any symptoms of rejection or infection. The controlled biodegradation of Bonelike ${ }^{\circledR}$ strongly enhances new bone formation and stimulates the revascularization of the bone tissue, therefore it may be used in a large spectrum of surgical applications. Other sites of implantation involving a large number of clinical studies with the long-term biocompatibility are underway to have further insight into the medical use of Bonelike ${ }^{\circledR}$.

\section{ACKNOWLEDGMENTS}

The authors express their thanks to the FCT - Fundação para a Ciência e Tecnologia for their support in this project through a grant \# BPD/6010/2001 \& BPD/20987/2004.

\section{REFERENCES}

1. Mohamed, A., Sudha, K., Kim, F., Karl, K. and Scott, P.B. (2003). Bone Graft Substitutes, In: Laurencin, C.T. (ed.), Chapter 7, Cell Based Approaches for Bone Graft Substitutes, ASTM - International, USA, p. 127.

2. Mellonig, J.T., Prewett, A.B. and Moyer, M.P. (1992). HIV Inactivation in a Bone Allograft, J. Periodontol., 63: 979.

3. Buck, B.E., Malinin, T.I. and Brown, M.D. (1989). Bone Transplantation and Human Immunodeficiency Virus. An Estimate of Risk of Acquired Immunodeficiency Syndrome (AIDS), Clin. Orthop., 240: 129.

4. Mary, E.A.R. and Raymond, A.Y. (1998). Bone Replacement Grafts - The Bone Substitutes, Dent. Clin. North Am., 42(3): 491.

5. Doron, I.I. and Amy, L.L. (2002). Bone Graft Substitutes, Oper. Tech. Plast. Reconsr. Surg., 9(4): 151.

6. Wright, S. (1999). Commentary The Bone-Graft Market in Europe, in Emerging Technologies in Orthopedics I: Bone Graft Substitutes, Bone Growth Stimulators and Bone Growth Factors by Datamonitor plc. p. 591.

7. Knaack, D., Goad, M.E.P., Aiolova, M., Christian, R., Ali, T., Promod, C. and Duke Lee, D. (1998). Resorbable Calcium Phosphate Bone Substitute, J. Biomed. Mater. Res., 43: 399.

8. Frayssinet, P., Trouillet, J.L., Rouquet, N., Azimus, E. and Autefage, A. (1993). Osseointegration Macroporous Calcium Phosphate Ceramics Having a Different Chemical Composition, Biomaterials, 14: 423. 
9. Klein, C.P.A.T., Driessen, A.A., Groot de K. and van den Hooff, A. (1983). Biodegradation Behavior of Various Calcium Phosphate Materials in Bone Tissue, J. Biomed. Mater. Res., 17: 769.

10. Daculsi, G. (1998). Biphasic Calcium Phosphate Concept Applied to Artificial Bone, Implant Coating and Injectable Bone Substitute, Biomaterials, 19: 1473.

11. Santos, J.D., Hastings, G.W. and Knowles, J.C. (1999). Sintered Hydroxyapatite Compositions and Method for the Preparation Thereof, Worldwide Applications (PCT), Patent No. 1189851.

12. Lopes, M.A., Santos, J.D., Monteiro, F.J. and Knowles, J.C. (1998). Glass Reinforced Hydroxyapatite: A Comprehensive Study of the Effect of Glass Composition on the Crystallography of the Composite, J. Biomed. Mater. Res., 39: 244.

13. Lopes, M.A., Monteiro, F.J. and Santos, J.D. (1999). Glass-reinforced Hydroxyapatite Composites: Fracture Toughness and Hardness Dependence on Microstructural Characteristics, Biomaterials, 20: 2085.

14. Lopes, M.A., Silva, R.F., Monteiro, F.J. and Santos, J.D. (2000). Microstructural Dependence of Young's and Shear Moduli of $\mathrm{P}_{2} \mathrm{O}_{5}$ Glass Reinforced Hydroxyapatite for Biomedical Applications, Biomaterials, 21: 749.

15. Lopes, M.A., Santos, J.D., Monteiro, F.J., Ohtsuki, C., Osaka, A., Kaneko, S. and Inoue, H. (2001). Push-out Testing and Histological Evaluation of Glass Reinforced Hydroxyapatite Composites Implanted in the Tibia of Rabbits, J. Biomed. Mater. Res., 54: 463.

16. Lobato, J.V., Hussain, N.S., Botelho, C.M., Rodrigues, J.M., Luís, A.L., Maurício, A.C., Lopes, M.A. and Santos, J.D. (2005). Assessment of the Potential of Bonelike ${ }^{\circledR}$ Graft for Bone Regeneration by using an Animal Model, Key. Eng. Mater., 877: 284-286.

17. Lobato, J.V., Hussain, N.S., Botelho, C.M., Mauricio, A.C., Afonso, A., Ali, N. and Santos, J.D. (2006). Assessment of Bonelike ${ }^{\circledR}$ Graft with a Resorbable Matrix using an Animal Model, Thin Solid Films, 515: 362.

18. Duarte, F., Santos, J.D. and Afonso, A. (2004). Medical Applications of Bonelike $^{\circledR}$ in Maxillofacial Surgery, Mater. Sci. Forum, 370: 455-456.

19. Gutierres, M., Hussain, N.S., Afonso, A., Almeida, L., Cabral, T., Lopes, M.A. and Santos, J.D. (2005). Biological Behaviour of Bonelike ${ }^{\circledR}$ Graft Implanted in Tibia of Humans, Key Eng. Mater., 1041: 284-286.

20. LeGeros, R.Z. (2002). Properties of Osteoconductive Biomaterials: Calcium Phosphates, Clin. Orthop., 395: 81.

21. Robert, D.A.G., Hanneke, G.T., Ronald, J.H. and Buma, P. (2005). Mechanism of Bone Incorporation of $\beta$-TCP Bone Substitute in Open Wedge Tibial Osteotomy in Patients, Biomaterials, 26: 6713.

22. Hirotsugu, H., Norio, A., Kimimitsu, O., Noritaka, F., Ohnishi, H., Okada, A., Nomura, S. and Maeda, T. (2004). A Histological Evaluation on Self setting $\alpha$-tricalcium Phosphate Applied in the Rat Bone Cavity, Biomaterials, 25: 431.

23. Meinel, L., Betz, O., Fajardo, R., Hofmann S., Nazarian, A., Cory, E., Hilbe, M., McCool, J., Langer, R., Vunjak-Novakovic, G., Merkle, H.P., 
Rechenberg, B., Kaplan, D.L. and Kirker-Head, C. (2006). Silk Based Biomaterials to Heal Critical Sized Femur Defects, Bone, 39: 922.

24. Lim, S.C., Lee, M.J. and Yeo, H.H. (2000). Effects of Various Implant Materials on Regeneration of Calvarial Defects in Rats, Pathol. Int., 50: 594.

25. Carano, R.A.D. and Filvaroff, E.H. (2003). Angiogenesis and Bone Repair, Drug Discov. Today, 21: 980.

26. Gutierres, M., Hussain, N.S., Lopes, M.A., Afonso, A., Cabral, A.T., Almeida, L. and Santos, J.D. (2006). Histomorphometric Measurements Histological and SEM Analyses of bone/implant Interface: Clinical Trials using Bonelike $^{\circledR}$ Granules, J. Orthop. Res., 24: 953. 